\title{
Prevalence of refractive errors in children with retinoblastoma
}

This article was published in the following Dove Medical Press journal: Clinical Ophthalmology

\author{
Victor MVillegas ${ }^{1,2}$ \\ Shuo-Chieh Wu' \\ Timothy G Murray² \\ Kara M Cavuoto' \\ Hilda Capo' \\ Craig A McKeown'
}

'Bascom Palmer Eye Institute, University of Miami Miller School of Medicine, FL, USA; ${ }^{2}$ Miami Ocular Oncology and Retina, Miami, FL, USA
Correspondence: Victor M Villegas Bascom Palmer Eye Institute, University of Miami Miller School of Medicine, 900 NW 17th Street, Miami, FL 33|36, USA Email v.villegas@med.miami.edu
Purpose: The main purpose of this study was to investigate refractive errors in children with unilateral and bilateral retinoblastoma (RB).

Methods: An institutional review board-approved consecutive retrospective cohort study was undertaken. Subjects underwent examination under general anesthesia as part of their $\mathrm{RB}$ follow-up, which included evaluation by a single pediatric ophthalmologist. Cycloplegic retinoscopy was performed and keratometry data assessed with a handheld Retinomax K Plus 3 keratorefractometer (Righton Ophthalmic Instruments).

Results: The study included 61 eyes of 37 subjects, with 18 (49\%) males and 19 females. Seventeen eyes ( $28 \%$ ) had hyperopia with spherical equivalent $\geq 3 \mathrm{D}$. Refractive astigmatism $\geq 1.5 \mathrm{D}$ was present in $32 \%$ of all eyes. Nine (38\%) subjects had anisometropia $\geq 2 \mathrm{D}$. Fifteen ( $63 \%)$ subjects had anisometropia $\geq 1 \mathrm{D}$.

Conclusion: This study reports the high proportion of amblyogenic refractive risk factors in children with RB, both in RB-affected eyes and contralateral normal eyes.

Keywords: retinoblastoma, hyperopia, myopia, astigmatism, amblyopia, anisometropia

\section{Introduction}

Retinoblastoma (RB) continues to represent the most common primary intraocular malignancy in children. ${ }^{1}$ Two-thirds of cases are nonheritable (nonfamilial), with normal life expectancy after therapy. ${ }^{2}$ However, a third of cases are heritable due to a germ-line mutation in the $R B$ gene. ${ }^{2}$ Newer chemotherapeutic strategies have allowed survival rates that approach $99 \%$ in developed countries. ${ }^{3}$ Globe-salvage rates and visual outcomes have also improved, especially since the introduction of selective intra-arterial chemotherapy and intravitreal chemotherapy, with overall primary salvage rates exceeding $70 \% .4$

Refractive errors, including anisometropia and hyperopia, are independent risk factors for amblyopia in children. ${ }^{6}$ A recent study with 3- to 5-year-old subjects $(n=3,869)$ established that unilateral amblyopia is present in $12.9 \%$ of subjects with hyperopia ( $\geq 3-<4 \mathrm{D}$ ) and 33.1\% with anisometropia ( $\geq 1-<2 \mathrm{D})$, whereas amblyopia alone is present in $4.4 \%$ and $3.6 \%$ of subjects without hyperopia or anisometropia, respectively. ${ }^{6}$ However, refractive errors in children with RB have not been studied. The main purpose of this study was to investigate refractive errors in children with a history of RB.

\section{Methods}

An institutional review board-approved (Larkin Community Hospital-3-012015) retrospective cohort study was undertaken confidentially and according to the tenets 
of the Declaration of Helsinki. Consent to review the medical records was waived by the board, due to less than minimal risk. A chart review of all children with a history of $\mathrm{RB}$ that had been evaluated under general anesthesia between 2014 and 2015 was conducted. All subjects were treated primarily with intra-arterial chemotherapy and $810 \mathrm{~nm}$ diode-laser ablation. Cryotherapy and radiation were not performed in any subject. Subjects underwent routine examination under anesthesia with cycloplegic retinoscopy and keratometry readings performed by a single pediatric ophthalmologist (VMV). Cycloplegic retinoscopy was performed after instillation of topical proparacaine $(0.5 \%)$, cyclopentolate $(1 \%)$, and tropicamide $(0.5 \%)$. Keratometry data were assessed with a handheld Retinomax K Plus 3 keratorefractometer (Righton Ophthalmic Instruments). Data gathered included age at diagnosis, age at refraction, sex, tumor location, primary treatment, spherical equivalent $(\mathrm{SE}$; sphere $+[0.5 \times$ cylinder]), plus refractive cylinder axis, flat keratometry $\left(\mathrm{K}_{1}\right)$, steep keratometry $\left(\mathrm{K}_{2}\right)$, and steepest corneal axis.

\section{Results}

The study included 61 eyes of 37 subjects, with 18 (49\%) males and 19 females. Thirteen subjects had either a phthisic eye or an enucleated socket. Bilateral RB was present in $16(24 \%)$ subjects, with a mean age at diagnosis of 12.0 months. Unilateral RB was present in $21(76 \%)$ subjects, with a mean age at diagnosis of 23.2 months. Age at diagnosis and cycloplegic refraction ranged from 1 month to 72 months. Nine (38\%) subjects had anisometropia $\geq 2$ D. Fifteen $(63 \%)$ subjects had anisometropia $\geq 1 \mathrm{D}$. Tables 1 and 2 summarize the study cohort and refractive characteristics.

When all eyes had been analyzed, 17 eyes (28\%) had hyperopia with $\mathrm{SE} \geq 3 \mathrm{D}$. Only two eyes from different subjects had myopia $>2 \mathrm{D}$. Refractive astigmatism $\geq 1.5 \mathrm{D}$ was present in $32 \%$ of all subject eyes. Mean SE was 2.7 $\pm 4.3 \mathrm{D}$. Mean refractive cylinder was $1.2 \pm 0.9 \mathrm{D}$. Mean plus refractive cylinder axis was $100.1^{\circ} \pm 46.2^{\circ}$. Mean $\mathrm{K}_{1}$ was $42.8 \pm 4.6 \mathrm{D}$.

Table I Characteristics of the cohort $(n=37)$

\begin{tabular}{|l|l|l|l|}
\hline & $\begin{array}{l}\text { Total } \\
(\mathbf{n}=\mathbf{3 7})\end{array}$ & $\begin{array}{l}\text { Unilateral } \\
\text { RB (n=2I) }\end{array}$ & $\begin{array}{l}\text { Bilateral } \\
\text { RB (n=l6) }\end{array}$ \\
\hline Male & $18(49 \%)$ & $9(43 \%)$ & $9(56 \%)$ \\
\hline Female & $19(51 \%)$ & $12(57 \%)$ & $7(44 \%)$ \\
\hline Enucleation/phthisis & $13(35 \%)$ & $5(24 \%)$ & $8(50 \%)$ \\
\hline Mean age at diagnosis (months) & 18.4 & 23.2 & 12 \\
\hline Anisometropia $\geq$ I D & $15(63 \%)$ & $10(63 \%)$ & $5(63 \%)$ \\
\hline Anisometropia $\geq 2$ D & $9(38 \%)$ & $5(31 \%)$ & $4(50 \%)$ \\
\hline
\end{tabular}

Abbreviation: RB, retinoblastoma.
Mean $\mathrm{K}_{2}$ was $45.3 \pm 2.1$ D. Mean steepest corneal axis was $91.9^{\circ} \pm 34.0^{\circ}$.

Analysis of the involved eye from subjects with unilateral RB ( $n=16)$ was then performed. Twelve eyes $(75 \%)$ had hyperopia with $\mathrm{SE} \geq 3 \mathrm{D}$. One eye had myopia $\geq 2 \mathrm{D}$. Refractive astigmatism $\geq 1.5 \mathrm{D}$ was present in $63 \%$ of the eyes. Mean SE was 6.9 \pm 5.7 D. Mean refractive astigmatism was $1.3 \pm 1.2 \mathrm{D}$. Mean plus refractive cylinder axis was $90.63^{\circ} \pm 45.3^{\circ}$. Mean $\mathrm{K}_{1}$ was 42.0 \pm 5.7 D. Mean $\mathrm{K}_{2}$ was $49.6 \pm 1.8 \mathrm{D}$. Mean steepest corneal axis was $74.9^{\circ} \pm 30.3^{\circ}$.

Analysis of the involved eye from subjects with bilateral RB ( $n=24)$ was then performed. Three eyes $(13 \%)$ had hyperopia with $\mathrm{SE} \geq 3 \mathrm{D}$. One eye had myopia $\geq 2 \mathrm{D}$. Refractive astigmatism $\geq 1.5 \mathrm{D}$ was present in $21 \%$ of the eyes. Mean SE was $1.2 \pm 1.6 \mathrm{D}$. Mean refractive astigmatism was $1.1 \pm 0.9 \mathrm{D}$. Mean plus refractive cylinder axis was $99.0^{\circ} \pm 41.6^{\circ}$. Mean $\mathrm{K}_{1}$ was $43.0 \pm 2.0$ D. Mean $\mathrm{K}_{2}$ was $44.7 \pm 2.6$ D. Mean steepest corneal axis was $103.6^{\circ} \pm 43.2^{\circ}$.

Analysis of the uninvolved contralateral eye from subjects with unilateral $R B(n=21)$ was then performed. Two eyes $(10 \%)$ had hyperopia with $\mathrm{SE} \geq 3 \mathrm{D}$. No eyes had myopia $\geq 2 \mathrm{D}$. Refractive astigmatism $\geq 1.5 \mathrm{D}$ was present in $24 \%$ of the eyes. Mean SE was $1.2 \pm 1.1$ D. Mean refractive astigmatism was $1.1 \pm 0.9 \mathrm{D}$. Mean plus refractive cylinder axis was $108.3^{\circ} \pm 57.5^{\circ}$. Mean $\mathrm{K}_{1}$ was 43.2 \pm 1.8 D. Mean $\mathrm{K}_{2}$ was 45.1 \pm 2.2 D. Mean steepest corneal axis was $91.5^{\circ} \pm 32.6^{\circ}$. Stratification of SE of all subject eyes by age-group at time of refraction was performed (Table 3). All three groups had similar prevalence of myopia, ranging from $4 \%$ to $6 \%$. The prevalence of hyperopia $\geq 2 \mathrm{D}$ decreased with age.

Analysis of RB eyes based on tumor location was then performed (Table 4). Eyes with macular RB had $>30 \%$ more hyperopia and refractive astigmatism compared to extramacular tumors.

\section{Discussion}

Management of patients with $\mathrm{RB}$ requires a multidisciplinary approach with a pediatric oncologist, ocular oncologist, and pediatric ophthalmologist. Significant improvements in globe-salvage prediction have been made during the last 5 years. ${ }^{5,7-10}$ However, data regarding refractive errors and amblyopic risk factors in children with $\mathrm{RB}$ continue to be scarce.

Large studies have validated strabismus and refractive errors being significant risk factors for unilateral amblyopia. ${ }^{6,11,12}$ Mild refractive astigmatism (1-2 D) has been associated with amblyopia in preschool children. ${ }^{6}$ The Multi-ethnic Pediatric Eye Disease Study evaluated over 
Table 2 Refractive profiles of all eyes $(n=6 I)$

\begin{tabular}{|l|l|l|l|}
\hline & $\begin{array}{l}\text { Unilateral RB eye } \\
(\mathbf{n}=16)\end{array}$ & $\begin{array}{l}\text { Bilateral RB eye } \\
(\mathbf{n}=\mathbf{2 4})\end{array}$ & $\begin{array}{l}\text { Contralateral unaffected } \\
\text { eye, unilateral RB (n=2 I) }\end{array}$ \\
\hline Hyperopia with SE $\geq 3$ D & $12(75 \%)$ & $3(13 \%)$ & $2(10 \%)$ \\
\hline Myopia $\geq 2$ D & $\mathrm{I}(6 \%)$ & $\mathrm{I}(4 \%)$ & 0 \\
\hline Refractive astigmatism $\geq \mathrm{I} .5 \mathrm{D}$ & $10(63 \%)$ & $5(21 \%)$ & $5(24 \%)$ \\
\hline Mean SE (D) & $6.9 \pm 5.7$ & $1.2 \pm 1.6$ & $1.2 \pm 1.1$ \\
\hline Mean refractive astigmatism (D) & $1.3 \pm 1.2$ & $1.1 \pm 0.9$ & $1.1 \pm 0.9$ \\
\hline Mean plus refractive cylinder axis $\left(^{\circ}\right)$ & $90.6 \pm 45.3$ & $99.0 \pm 41.6$ & $108.3 \pm 57.5$ \\
\hline Mean corneal $\mathrm{K}_{1}(\mathrm{D})$ & $42.0 \pm 5.7$ & $43.0 \pm 2.0$ & $43.2 \pm 1.8$ \\
\hline Mean corneal $\mathrm{K}_{2}(\mathrm{D})$ & $49.6 \pm 1.8$ & $44.7 \pm 2.6$ & $45.1 \pm 2.2$ \\
\hline Steepest corneal axis $\left(^{\circ}\right)$ & $74.9 \pm 30.3$ & $103.6 \pm 43.2$ & $91.5 \pm 32.6$ \\
\hline
\end{tabular}

Abbreviations: RB, retinoblastoma; SE, spherical equivalent.

6,000 children, and found refractive error to be the most common risk factor leading to amblyopia. ${ }^{11}$ Anisometropia, refractive astigmatism, and amblyopia seem to affect Hispanic children at a higher rate than other ethnic groups. ${ }^{6,11}$ The Vision in Preschoolers study group determined the prevalence of refractive astigmatism ( $\geq 1 \mathrm{D}$ ) in 3,869 children to be $28.9 \%$. Hispanic patients had the highest prevalence of astigmatism $>3.5 \mathrm{D}$ (11.1\%) among all ethnic groups studied. ${ }^{13}$ In our study, the most common refractive error risk was refractive astigmatism. Astigmatism $\geq 1.5 \mathrm{D}$ was present in $32 \%$ of all eyes, and analysis of refractive astigmatism in eyes without RB showed $24 \%$ of eyes had astigmatism $\geq 1.5 \mathrm{D}$. The study prevalence of astigmatism contrasts with previous historical controls. ${ }^{6,13}$ Hyperopia $>2$ D has also been associated with amblyopia development in preschool children. ${ }^{6}$ Hyperopia seems to be associated with amblyopia in a dose-dependent fashion. ${ }^{6,11,12}$ In our study, hyperopia $>3$ D was present in $28 \%$ of eyes. Eyes without RB had a low prevalence $(10 \%)$ of hyperopia $>3 \mathrm{D}$ compared to eyes with RB. Eyes with macular RB had the highest mean $\mathrm{SE}$ and refractive astigmatism. Prevalence of hyperopia

Table 3 Prevalence of hyperopia and myopia in all subject eyes stratified by age at cycloplegic refraction

\begin{tabular}{|l|l|l|l|}
\hline & $\begin{array}{l}\text { I-I I months } \\
(\mathbf{n = 2 0 )}\end{array}$ & $\begin{array}{l}\text { I 2-23 months } \\
(\mathbf{n = I 7 )}\end{array}$ & $\begin{array}{l}\mathbf{2 4 - 7 2} \text { months } \\
(\mathbf{n}=\mathbf{2 4})\end{array}$ \\
\hline $\begin{array}{l}\text { Hyperopia } \\
(\mathrm{SE} \geq+2.0 \mathrm{D})\end{array}$ & $\mathrm{II}(55 \%)$ & $6(35 \%)$ & $6(25 \%)$ \\
\hline $\begin{array}{l}\text { Myopia } \\
(\mathrm{SE} \leq-\mathrm{I} .0 \mathrm{D})\end{array}$ & I (5\%) & $\mathrm{I}(6 \%)$ & $\mathrm{I}(4 \%)$ \\
\hline Mean SE & 3.1 & 2.4 & 2.7 \\
\hline SD & 3.7 & 3.4 & 5.4 \\
\hline Standard error & 0.8 & 0.8 & 1.2 \\
\hline
\end{tabular}

Abbreviation: SE, spherical equivalent.
(35\%-55\%) and myopia (4\%-6\%) also seem to be higher in RB patients (1-72 months old) than a previous study, which reported the prevalence of hyperopia and myopia to be $25.56 \%$ and $1.20 \%$ in 1,507 non-Hispanic children aged 6-72 months old (Table 3). ${ }^{14}$ Neuroimaging studies have also shown that eyes with RB have shorter axes, which correlates inversely with tumor volume. ${ }^{15}$ The high prevalence of hyperopia in patients with RB may also be partially explained by the hyperopic shift associated with posteriorpole tumor involvement.

Significant anisometropia ( $\geq 0.5 \mathrm{D}$ ) has been associated with refractive amblyopia in $>90 \%$ of children. ${ }^{6}$ Hyperopic anisometropia seems to have the lowest threshold for causing unilateral amblyopia. In our study, 15 subjects (63\%) had anisometropia $\geq 1 \mathrm{D}$, and nine subjects (38\%) had anisometropia $\geq 2 \mathrm{D}$.

A recent study performed in Taiwan found with-the-rule astigmatism to be the most common. ${ }^{16}$ The cyclorefractive cylinder axis was similar to the corneal cylinder axis. ${ }^{16}$ Correspondingly, with-the-rule astigmatism was the most common in our study, including nontumor eyes.

Visual acuity potential in eyes with RB is not well understood. Historically, eyes with RB had a guarded prognosis. Recent studies have demonstrated improved visual outcomes. ${ }^{17-23} \mathrm{~A}$ study that evaluated visual outcomes in 12 children with macular RB found that $80 \%$ of eyes with

Table 4 Mean refractive error and RB location

\begin{tabular}{|l|l|l|}
\hline & $\begin{array}{l}\text { Mean spherical } \\
\text { equivalent (D) }\end{array}$ & $\begin{array}{l}\text { Mean refractive } \\
\text { astigmatism (D) }\end{array}$ \\
\hline Macular RB $(n=28)$ & $3.7 \pm 5.0$ & $1.5 \pm 1.0$ \\
\hline Extramacular RB $(n=12)$ & $2.6 \pm 5.3$ & $1.0 \pm 0.67$ \\
\hline
\end{tabular}

Abbreviation: $\mathrm{RB}$, retinoblastoma. 
macular involvement had improvement of visual acuity following occlusion therapy. ${ }^{21}$ This suggests that subjects with macular RB have diminished vision beyond the level expected for the burden of ocular pathology. Our study found a significant prevalence of high refractive errors in children with RB that may lead to amblyopia.

Limitations of our study include its retrospective nature and sample size. Because RB is a rare disease, extensive studies are likely to be limited. Chemotherapy, number of laser treatments, tumor size, tumor-growth pattern, visual acuity, cataracts, and clinical changes were not evaluated. Further studies may elucidate if any correlation with refractive errors exists.

This study reports the high proportion of children with $\mathrm{RB}$ that have amblyogenic refractive risk factors in both RB-affected eyes and normal contralateral eyes in unilateral cases. It is likely that significant expertise in pediatric refraction and amblyopia treatment may help these children achieve maximal visual potential. Further studies are needed to evaluate the prevalence of amblyopia in children with RB.

\section{Ethical approval}

An institutional review board-approved (Larkin Community Hospital-3-012015) retrospective cohort study was undertaken confidentially and according to the tenets of the Declaration of Helsinki.

\section{Acknowledgments}

The abstract of this paper was presented at the American Association of Pediatric Ophthalmology and Strabismus Annual Meeting (Vancouver, Canada 2016) as a poster presentation with interim findings, supported in part by the National Institutes of Health, Bethesda, MD (grant P30-EY014801) and an unrestricted grant to the University of Miami from Research to Prevent Blindness, New York, NY, USA.

\section{Disclosure}

The authors report no conflicts of interest in this work.

\section{References}

1. Kivelä T. The epidemiological challenge of the most frequent eye cancer: retinoblastoma, an issue of birth and death. Br J Ophthalmol. 2009;93(9):1129-1131.

2. Ghassemi F, Chams H, Sabour S, et al. Characteristics of germline and non-germline retinoblastomas. J Ophthalmic Vis Res. 2014;9(2): 188-194.

3. Broaddus E, Topham A, Singh AD. Survival with retinoblastoma in the USA: 1975-2004. Br J Ophthalmol. 2009;93(1):24-27.
4. Shields CL, Lally SE, Leahey AM, et al. Targeted retinoblastoma management: when to use intravenous, intra-arterial, periocular, and intravitreal chemotherapy. Curr Opin Ophthalmol. 2014;25(5):374-385.

5. Shields CL, Manjandavida FP, Lally SE, et al. Intra-arterial chemotherapy for retinoblastoma in 70 eyes: outcomes based on the International Classification of retinoblastoma. Ophthalmology. 2014;121(7): 1453-1460.

6. Pascual M, Huang J, Maguire MG, et al; Vision In Preschoolers (VIP) Study Group. Risk factors for amblyopia in the vision in preschoolers study. Ophthalmology. 2014;121(3):622-629.

7. Francis JH, Abramson DH, Gobin YP, et al. Efficacy and toxicity of second-course ophthalmic artery chemosurgery for retinoblastoma. Ophthalmology. 2015;122(5):1016-1022.

8. Ossandón D, Zanolli M, Pérez V, et al. Using cost-effective intra-arterial chemotherapy to treat retinoblastoma in Chile. J AAPOS. 2014;18(6): 617-619.

9. Kaliki S, Srinivasan V, Gupta A, Mishra DK, Naik MN. Clinical features predictive of high-risk retinoblastoma in 403 Asian Indian patients: a case-control study. Ophthalmology. 2015;122(6):1165-1172.

10. Francis JH, Abramson DH, Gaillard MC, Marr BP, Beck-Popovic M, Munier FL. The classification of vitreous seeds in retinoblastoma and response to intravitreal melphalan. Ophthalmology. 2015;122(6): 1173-1179.

11. Multi-ethnic Pediatric Eye Disease Study Group. Prevalence of amblyopia and strabismus in African American and Hispanic children ages 6 to 72 months the multi-ethnic pediatric eye Disease Study. Ophthalmology. 2008;115(7):1229-1236.e1.

12. Friedman DS, Repka MX, Katz J, et al. Prevalence of amblyopia and strabismus in white and African American children aged 6 through 71 months the Baltimore Pediatric Eye Disease Study. Ophthalmology. 2009;116(11):2128-2134.e1-e2.

13. Ying GS, Maguire MG, Cyert LA, et al; Vision In Preschoolers (VIP) Study Group. Prevalence of vision disorders by racial and ethnic group among children participating in head start. Ophthalmology. 2014; 121(3):630-636.

14. Wen G, Tarczy-Hornoch K, McKean-Cowdin R, et al; Multi-Ethnic Pediatric Eye Disease Study Group. Prevalence of myopia, hyperopia, and astigmatism in non-Hispanic white and Asian children: multi-ethnic pediatric eye disease study. Ophthalmology. 2013;120(10):2109-2116.

15. de Graaf P, Knol DL, Moll AC, Imhof SM, Schouten-van Meeteren AY, Castelijns JA. Eye size in retinoblastoma: MR imaging measurements in normal and affected eyes. Radiology. 2007;244(1):273-280.

16. Lai YH, Hsu HT, Wang HZ, Chang CH, Chang SJ. Astigmatism in preschool children in Taiwan. J AAPOS. 2010;14(2):150-154.

17. Hall LS, Ceisler E, Abramson DH. Visual outcomes in children with bilateral retinoblastoma. J AAPOS. 1999;3(3):138-142.

18. Tsimpida M, Thompson DA, Liasis A, et al. Visual outcomes following intraophthalmic artery melphalan for patients with refractory retinoblastoma and age appropriate vision. Br J Ophthalmol. 2013;97(11):1464-1470.

19. Schefler AC, Cicciarelli N, Feuer W, Toledano S, Murray TG. Macular retinoblastoma: evaluation of tumor control, local complications, and visual outcomes for eyes treated with chemotherapy and repetitive foveal laser ablation. Ophthalmology. 2007;114(1):162-169.

20. Payne JF, Hutchinson AK. Hubbard GB 3rd, Lambert SR. outcomes of cataract surgery following radiation treatment for retinoblastoma. J AAPOS. 2009;13(5):454-458.e3.

21. Watts $\mathrm{P}$, Westall $\mathrm{C}$, Colpa L, et al. Visual results in children treated for macular retinoblastoma. Eye. 2002;16(1):75-80.

22. Batra A, Pushker N, Venkatesh P, Arora T, Tewari R, Bakhshi S. Long-term visual outcomes in intraocular retinoblastoma with eye preservation. Clin Transl Oncol. 2016;18(10):1034-1038.

23. Soliman SE, VandenHoven C, Mackeen LD, Gallie BL. Vision and visual potential for perifoveal retinoblastoma after optical coherence tomographic-guided sequential laser photocoagulation. $\mathrm{Br}$ J Ophthalmol. Epub 2018 Jul 5. 


\section{Publish your work in this journal}

Clinical Ophthalmology is an international, peer-reviewed journal covering all subspecialties within ophthalmology. Key topics include: Optometry; Visual science; Pharmacology and drug therapy in eye diseases; Basic Sciences; Primary and Secondary eye care; Patien Safety and Quality of Care Improvements. This journal is indexed on

Submit your manuscript here: http://www.dovepress.com/clinical-ophthalmology-journal
Dovepress

PubMed Central and CAS, and is the official journal of The Society of Clinical Ophthalmology (SCO). The manuscript management system is completely online and includes a very quick and fair peer-review system, which is all easy to use. Visit http://www.dovepress.com/ testimonials.php to read real quotes from published authors. 